\title{
Trainee doctors propose minimum standards for call rooms
}

Cite as: CMAJ 2019 May 21;191:E568-9. doi: 10.1503/cmaj.109-5750

Posted on cmajnews.com on May 1, 2019.

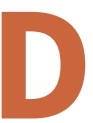

irty sheets and bathrooms, broken lights and toilets, poor security and little privacy - the conditions of rest spaces for resident doctors provoked gasps at the recent Canadian Conference on Medical Education. But for residents, the grim state of some call rooms isn't shocking, said Dr. Avery Wynick, a family medicine resident at the University of Alberta. "We've all seen the huge discrepancies."

Resident Doctors of Canada is proposing national minimum standards for call rooms. Medical trainee contracts already include some standards, Wynick said. But they are vague, hard to enforce and often worded "more as recommendations." They also vary across the country.

In some cases, trainees working 26-hour shifts don't have access to a bed, let alone a private room. One hospital provided Wynick with an emergency room stretcher with stained sheets, two beds over from the patient she had just treated. Other doctors recall sleeping wherever they could, including on medical equipment.

It's a patient safety issue, as well as a threat to physician well-being, Wynick said. In a 2018 survey, one in five Canadian residents admitted to making medical errors because of workrelated fatigue.
"Resident fatigue should be mitigated to improve patient care outcomes, as well as to protect residents from guilt, anxiety and burnout from these errors," said Wynick. "While fixing call rooms won't solve these problems, it's something that can be objectively improved."

At a minimum, residents on call should have access to clean and secure sleeping quarters, bathroom facilities and some elements of a workspace, she said. These should include basics such as a bed and clean linens, lighting and temperature control, functioning toilets and sinks, showers with hot water, locking doors or lockers, a desk and a chair, a computer or WiFi, and regular housekeeping.

"None of these things seem unreasonable or unattainable by any measure," said Wynick. Many hospitals already provide these basics, and others could meet the proposed standards without extensive remodelling or overhaul, she said.

Earlier this year, the NHS Staff and Learners' Mental Wellbeing Commission in Britain emphasized "the importance of psychologically safe and confidential

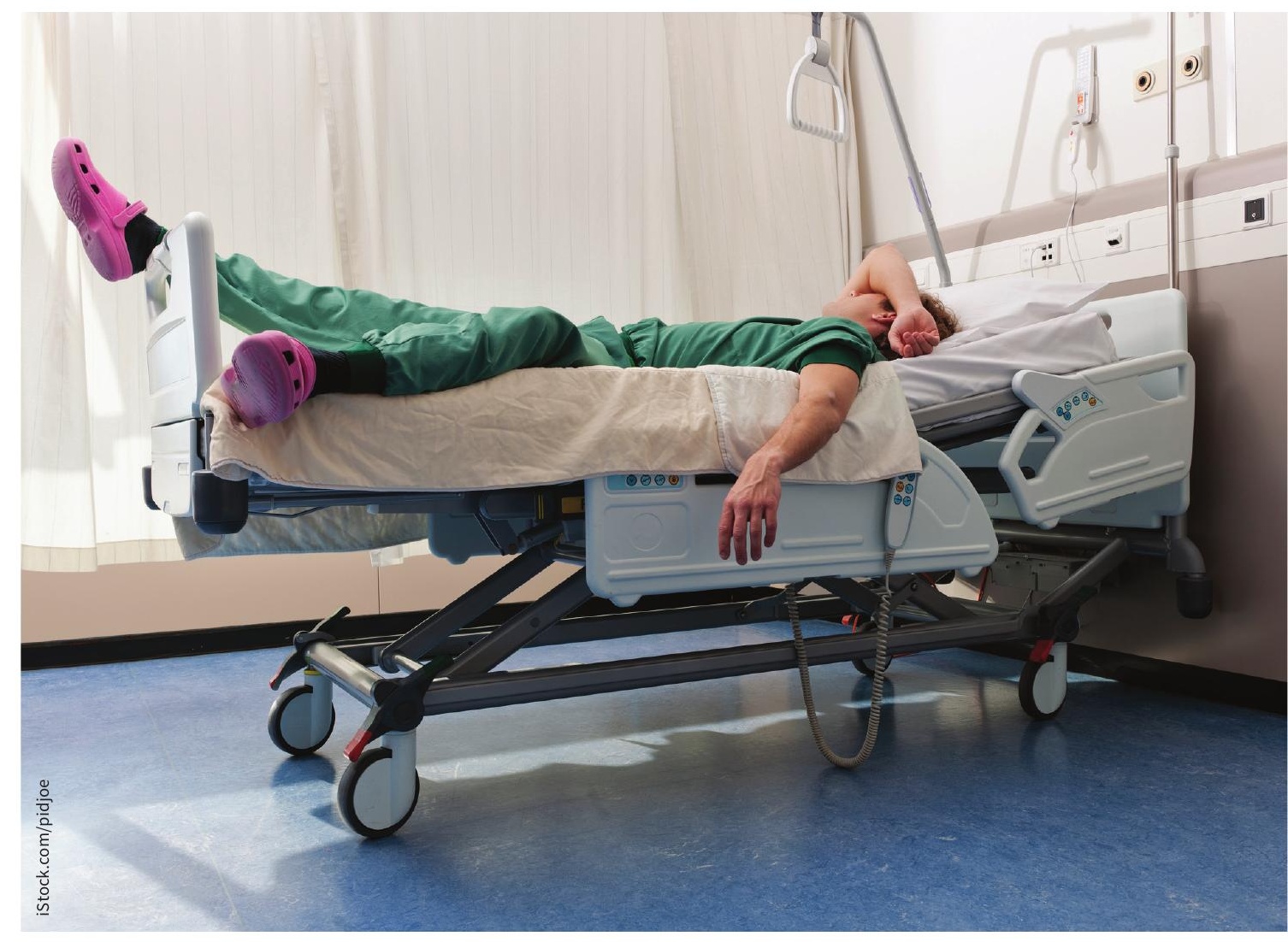

Accommodations for resident doctors to rest while on call vary widely. 
spaces away from patients and the public where staff have privacy to socialize and informally debrief." British junior doctors have demanded the reinstatement of call rooms to improve rest and reduce risk of fatigue-related car accidents on their way home from work.

In Australia, however, there's been a move to phase out call rooms based on the argument that doctors are no more special than other staff and should be awake if they're scheduled to work. According to Wynick, that argument doesn't make sense in Canada, where no other staff are required to work 26-hour shifts.

The culture of medicine is part of the problem, as residents may feel pressure to avoid rest. Many trainees encounter unacceptable call room conditions but few make official complaints, Wynick said. "Without communicating these inadequacies, they won't come to the attention of people who would advocate on our behalf."

Lauren Vogel, CMAJ 